\title{
Avaliação macroscópica, microscópica e histomorfométrica do tecido cicatricial pós- cirúrgico de eqüinos submetidos a duas técnicas de neurectomia digital
}

[Macroscopic, microscopic, and histomorphometric evaluation of post-operative scar tissue in horses submitted to two techniques for digital neurectomy]

\author{
A. Escobar ${ }^{1}$, J.J.M. Rio Tinto ${ }^{2}$, A.C. Vasconcelos $^{3}$, M.A. Rachid ${ }^{3}$, G.E.S. Alves ${ }^{4}$, R.R. Faleiros ${ }^{4 *}$ \\ ${ }^{1}$ Aluno de pós-graduação - FCAV-UNESP - Jaboticabal, SP \\ ${ }^{2}$ Escola de Veterinária - PUC-Minas - Betim, MG \\ ${ }^{3}$ Instituto de Ciências Biológicas - UFMG - Belo Horizonte, MG \\ ${ }^{4}$ Escola de Veterinária - UFMG \\ Caixa Postal 567 \\ 30123-970 - Belo Horizonte, MG
}

\begin{abstract}
RESUMO
Avaliou-se macro e microscopicamente o tecido cicatricial pós-operatório de eqüinos submetidos a duas técnicas de neurectomia digital: guilhotina (TG) e stripping (TS). Decorridos 14 meses das cirurgias, foram colhidas 32 amostras de tecido cicatricial em quatro éguas, que tiveram os membros submetidos a ambas as técnicas. À macroscopia, verificaram-se as dimensões da cicatriz do coto proximal e a distância entre os cotos proximal e distal. À microscopia, foi quantificada a proporção de tecido nervoso regenerado por meio de histomorfometria. Não houve diferença nas dimensões do tecido cicatricial, contudo a distância entre cotos foi 5,6 vezes maior na TS $(\mathrm{P} \leq 0,001)$. Histologicamente, observou-se a presença de tecido conjuntivo frouxo e denso, macrófagos e fibras nervosas delgadas em ambas as técnicas cirúrgicas. Estruturas nodulares, compostas por fascículos nervosos, foram visualizadas em 56,2\% (9/16) das amostras colhidas em nervos submetidos à TS. As porcentagens médias de tecido nervoso no tecido cicatricial foram de $0,31 \%$ na TG e $2,6 \%$ na TS $(\mathrm{P} \leq 0,001)$. Concluiu-se que o retorno à sensibilidade nervosa deve demorar mais a ocorrer após a TS, devido à maior distância entre cotos. A maior proporção de tecido nervoso sugere que essa técnica favorece a regeneração nervosa.
\end{abstract}

Palavras-chave: eqüino, neurectomia, dor, neuroma, reinervação

\begin{abstract}
The post-operative healed tissues in horses submitted to two digital neurectomy techniques, the guilhotine (GT) and the stripping (ST), were evaluated by macroscopy and microscopy. Fourteen months after surgery, 32 samples of scar tissue were collected from four mares that had the members experimentally submitted to both surgical techniques. By macroscopy, the dimensions of the scar tissue of the proximal stump and the distance between nerve stumps were taken. By microscopy, the proportion of nervous tissues in the scar tissue was quantified by histomorphometry. There were no differences between the scar tissue dimensions, but the distance between stumps was 5.6-fold greater in ST subjects. Histologically, connective tissue, macrophages, and thin nervous fibers were observed in scar tissue present in animals of both groups. Nodular structures composed by nervous fascicules were visualized in 56.2\% (9/16) of the samples collected from the ST group. The mean percentage of the nervous tissue in scar tissue was $0.31 \%$ in GT samples and $2.6 \%$ in ST samples $(P \leq 0.001)$. After $S T$, a longer time to the return of the sensibility may occur due to the greater distance between stumps. However, greater proportion of nervous tissue in the scar tissue suggests that the use of this technique favors nervous regeneration.
\end{abstract}

Keywords: horse, neurectomy, pain, neuromas, reinervation

Recebido em 27 de junho de 2007

Aceito em 27 de junho de 2008

*Autor para correspondência (corresponding author)

E-mail: faleiros@ufmg.br 


\section{INTRODUÇÃO}

O estímulo doloroso a injúrias traumáticas pode induzir a uma série de alterações fisiológicas como desconforto, redução no consumo alimentar e aumento do tempo de convalescença e cicatrização da ferida. A hiperalgesia causada por uma lesão tecidual não é apenas restrita ao local da lesão, mas também a áreas não lesadas que circundam essa região, diminuindo o limiar mecânico nociceptivo desses sítios (Duque et al., 2004). Nos últimos anos, a preocupação com o tratamento da dor aguda vem aumentando mesmo com o avanço farmacológico. Entretanto, quando a dor adquire um caráter crônico, o tratamento terapêutico pode se tornar longo, dispendioso e ineficaz (Faleiros et al., 1997).

A neurectomia digital palmar vem sendo utilizada em eqüinos refratários à terapêutica convencional, que sofrem fraturas de falange distal e doenças degenerativas como a calcificação da cartilagem da falange distal e a doença do navicular. Esse procedimento, apesar de não impedir o progresso da doença, melhora substancialmente a qualidade de vida do animal e aumenta sua vida útil (Jackman et al., 1993; Turner et al., 1995). Diversas técnicas vêm sendo desenvolvidas com o intuito de minimizar as complicações pós-cirúrgicas, como a dessensibilização incompleta da área afetada, a regeneração do segmento do nervo retirado e a formação de neuromas dolorosos (Schneider et al., 1985; Cummings et al., 1988; Haugland et al., 1992; Dabareiner et al., 1997).

Dabareiner et al. (1997) compararam a técnica de guilhotina com diferentes técnicas de laser por $\mathrm{CO}_{2}$ e relataram a formação de neuromas dolorosos em todos os casos, sendo a técnica de guilhotina a que produziu menores complicações pós-operatórias. Um estudo histopatológico realizado nos cotos neurectomizados de eqüídeos, quatro meses após as cirurgias, descreveu aumento da espessura do epineuro e do perineuro, associado com degeneração axonal, caracterizando a formação de neuromas (Said et al., 1984).

A técnica de stripping, descrita por Black (1992), utiliza duas incisões de pele para retirar um fragmento maior de nervo. Faleiros et al. (2008) observaram, 14 meses após as cirurgias, que o retorno da sensibilidade foi menor quando utilizaram a técnica de stripping $(18,8 \%)$ quando comparado à técnica de guilhotina $(37,0 \%)$.

O objetivo deste estudo foi avaliar macroscopicamente, microscopicamente e por meio de histomorfometria o tecido cicatricial pós-operatório de eqüinos submetidos a duas técnicas de neurectomia digital: a tradicional de guilhotina (TG) e a alternativa de stripping (TS).

\section{MATERIAL E MÉTODOS}

Foram utilizadas quatro éguas adultas, consideradas sadias após avaliações clínica e laboratorial (hemograma completo e fibrinogênio plasmático), oriundas da Fazenda Experimental de Pedro Leopoldo. Esses animais tiveram os quatro membros submetidos experimentalmente a duas técnicas de neurectomia digital, a técnica de Guilhotina e a técnica de stripping, totalizando dois grupos com 16 nervos cada, conforme descrito por Faleiros et al. (2008).

Quatorze meses após a realização das cirurgias, os animais foram sacrificados. Ao exame posmortem, a pele da região da quartela foi cuidadosamente removida, e o tecido subcutâneo dissecado de forma a expor o tecido cicatricial que se formou próximo aos cotos do nervo previamente seccionado. Com o auxílio de um paquímetro, realizou-se a medida da distância entre cotos proximal e distal. O tecido cicatricial próximo ao coto proximal foi, então, removido, e sua espessura e seu comprimento foram também registrados com auxílio do mesmo instrumento. Após medidas, estas amostras foram fixadas em formalina a $10 \%$, incluídas em parafina e seccionadas em cortes transversais, que foram corados com hematoxilina-eosina e tricômio de Masson, conforme técnicas de rotina (Luna, 1968).

As imagens produzidas num microscópio ${ }^{1}$ com objetiva planapocromática de 10 vezes, conectado a uma câmera ${ }^{2}$, eram enviadas ao computador através de uma placa digitalizadora ${ }^{3}$ para seu processamento.

Histologicamente observou-se a presença ou a ausência de: proliferação axonal, tecido

${ }^{1}$ Zeiss Axiolab - Alemanha.

${ }^{2} \mathrm{JVC} / \mathrm{TK}-1270$ - Color Vídeo Câmera - Alemanha.

${ }^{3}$ Frame Grabber - MiroMOVIE PRO - Alemanha. 
conjuntivo e infiltrado inflamatório. Para a análise histomorfométrica, doze amostras de cada técnica foram selecionadas aleatoriamente $\mathrm{e}$ todos os campos presentes em cada uma das lâminas processadas foram quantificados. Através do monitor, definia-se o limite de resolução das fibras nervosas para identificar seletivamente e individualmente as diferentes áreas. Com isso, por meio de um analisador de imagens ${ }^{4}$, foram diferenciados em regiões formadas por tecido nervoso periférico e regiões formadas por qualquer outro tipo celular. A relação entre a área dessas duas regiões foi feita para se obter a porcentagem de tecido nervoso em cada amostra.

Todos os dados numéricos foram tabulados, e a comparação entre grupos foi realizada por meio do teste $t$, considerando como significantes as diferenças equivalentes a $\mathrm{P} \leq 0,05$.

\section{RESULTADOS E DISCUSSÃO}

O exame macroscópico revelou aumento de volume cicatricial em todos os cotos proximais. $\mathrm{Na}$ maioria dos membros, essas alterações não foram evidentes no coto distal. Segundo Schneider et al. (1985), esses achados podem ser classificados como neuromas, caracterizados como espessamento não neoplásico que ocorre na extremidade de um nervo seccionado, e são esperados após este tipo de procedimento cirúrgico. Geralmente, o que caracteriza um neuroma como patológico é o aumento da sensibilidade dolorosa local, que pode ser promovida pela proliferação desordenada de axônios no tecido fibroso ou pelo contato direto dos axônios com o tecido fibroso cicatricial que favoreceria a indução anormal de sinais nociceptivos ascendentes (Schneider et al. 1985). O exame clínico aos 14 meses após a cirurgia não revelou sensibilidade dolorosa em nenhum dos cotos proximais, descartando-se, assim, a possibilidade de formação de neuromas dolorosos (Faleiros et al., 2008).

As dimensões médias do tecido cicatricial do coto proximal foram, respectivamente, para as técnicas TG e TS de $6,44 \pm 1,25 \mathrm{~mm}$ e $6,78 \pm 0$, $68 \mathrm{~mm}$ de diâmetro e $13,6 \pm 1,58 \mathrm{~mm}$ e $13,6 \pm 1,25 \mathrm{~mm}$ de comprimento (Fig. 1); não houve diferença estatística entre elas $(\mathrm{P}>0,05)$.

${ }^{4}$ KS300 versão 2.0 Kontron Elektronic GMBH - Alemanha.
Esses achados sugerem que a agressão promovida pela secção do nervo foi semelhante em ambas as técnicas e que as condições inflamatórias foram similares no período pósoperatório.
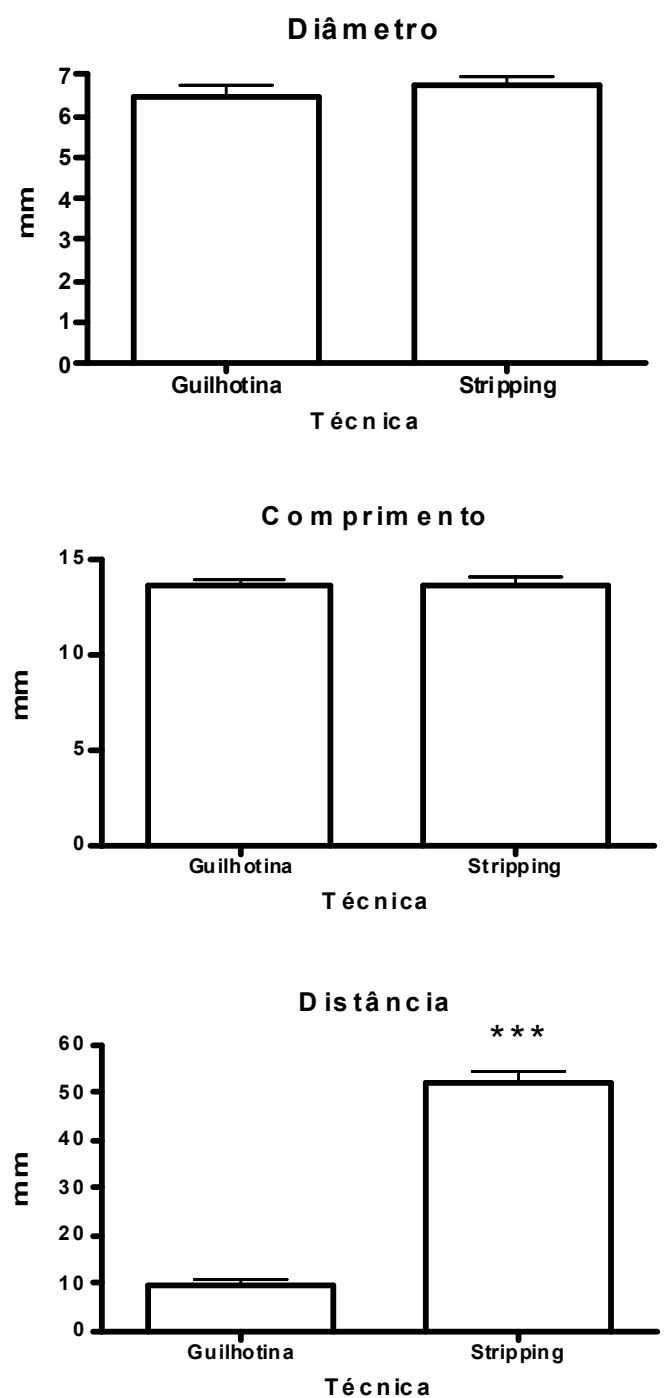

Figura 1. Porcentagem média ( \pm erro-padrão) do diâmetro e do comprimento do tecido cicatricial póscirúrgico do coto proximal e da distância entre cotos de eqüinos submetidos a duas técnicas de neurectomia digital: guilhotina e stripping. $* * *$ Diferem entre técnicas (teste $\mathrm{t}, \mathrm{P} \leq 0,001$ )

A distância média entre os cotos proximal e distal foi de $51,9 \pm 10,1 \mathrm{~mm}$ em TS, valor cerca de cinco vezes maior que a da TG, de 9,28 $\pm 6,67 \mathrm{~mm}$ (Fig. 1). Em 25\% (4/16) dos nervos operados com TG, observou-se que os cotos se apresentavam unidos pelo tecido cicatricial. Esse 
fato não ocorreu no grupo de nervos operados pela TS (0/16). No estudo clínico, seis membros $(37,5 \%)$ operados pela TG e três $(18,8 \%)$ operados pela TS apresentavam sensibilidade nos talões (Faleiros et al., 2008). O fato de haver retorno de sensibilidade nos membros de animais operados por TS demonstra que ramos oriundos de outros nervos podem também atuar no processo de reinervação.

$\mathrm{Na}$ análise histológica, observaram-se tecido conjuntivo frouxo altamente vascularizado na região periférica e proliferação de fibras de tecido conjuntivo denso na região central do tecido, em ambos os grupos. Agregados pequenos e focais de eosinófilos e de alguns linfócitos foram observados em 6,2\% (1/16) dos tecidos operados com a TG e em $12,5 \%(2 / 16)$ dos tecidos operados com a TS. Turner et al. (1995) descreveram formação de tecido fibrovascular e processo inflamatório crônico oito semanas após a realização de diferentes técnicas de neurectomia. Delistoianov et al. (2006) observaram formação de tecido conjuntivo e infiltrado inflamatório em eqüinos após a utilização de duas técnicas de neurorrafia, até 180 dias após as cirurgias.

Estruturas nodulares compostas de fascículos nervosos foram visualizadas em 56,2\% (9/16) das amostras colhidas em nervos submetidos à TS (Fig. 2), contudo, secções de fibras nervosas delgadas foram observadas centralmente em ambas as técnicas. O tecido nervoso periférico possui grande capacidade regenerativa (Stopiglia et al., 1998; Grecco et al., 2003), tornando plausível a hipótese de regeneração em cavalos submetidos à neurectomia. Um estudo retrospectivo realizado por Jackman et al. (1993) relatou que $74 \%$ dos cavalos não apresentaram claudicação um ano após as cirurgias e apenas $63 \%$ deles não apresentavam sinais de dor após dois anos, sugerindo maior regeneração nervosa com o passar do tempo. Foi observado retorno da sensibilidade do casco, em média, 306 dias após a neurectomia realizada pela $\mathrm{TG}$, sendo este período ainda menor em cavalos submetidos à neurectomia por técnicas a laser (Dabareiner et al., 1997). Com relação à técnica a TS, o único relato de retorno da sensibilidade ocorreu após dois anos (Black, 1992).

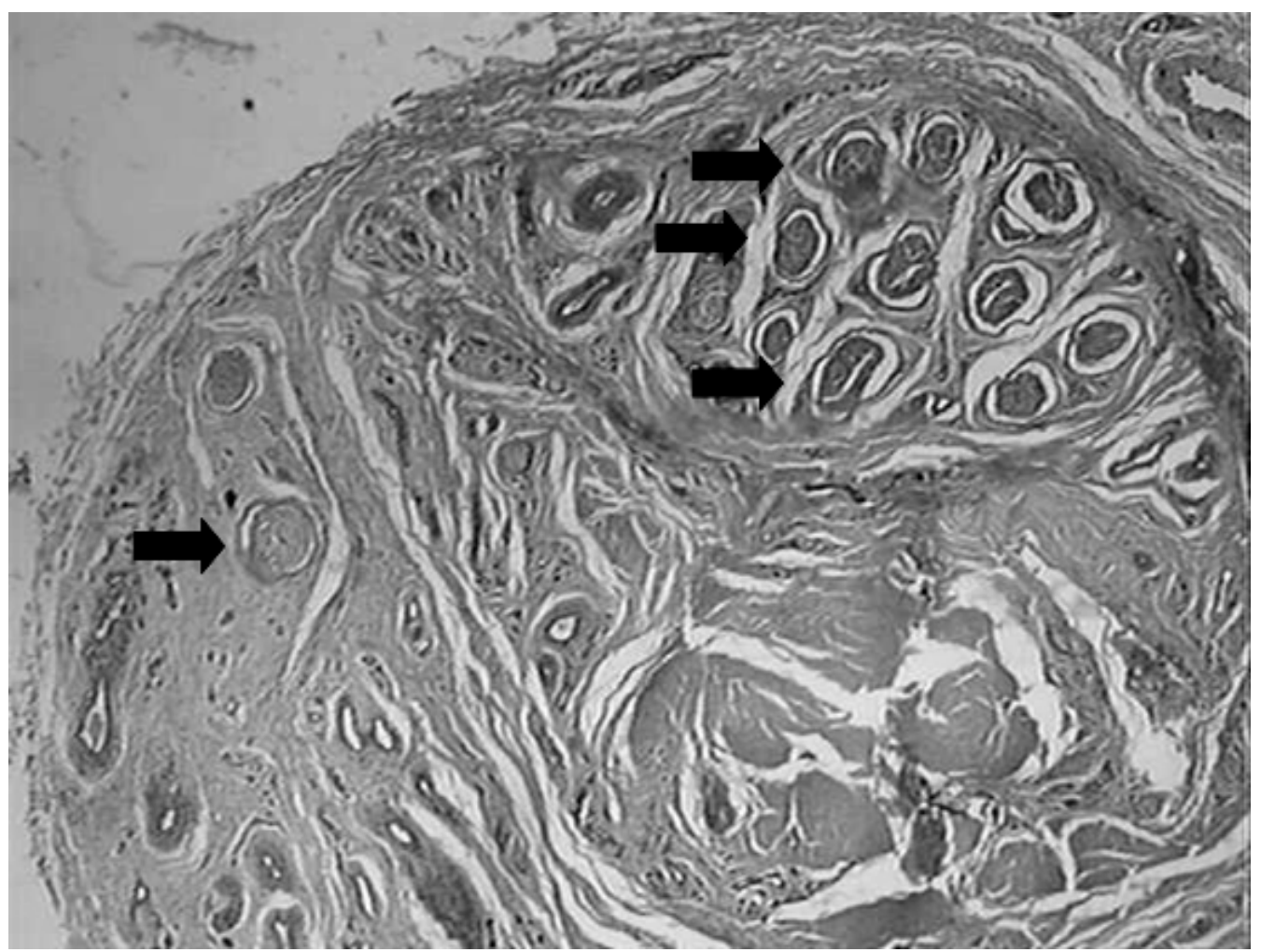

Figura 2. Formação nodular de tecido cicatricial pós-cirurgico com presença de fascículos nervosos nos animais tratados com a TS, indicados pelas setas. HE, obj. 10x. 
A análise histomorfométrica determinou a porcentagem de tecido nervoso em relação à totalidade de tecido cicatricial, constituído de tecido conjuntivo frouxo e denso, vasos sangüíneos e células inflamatórias. As porcentagens médias de tecido nervoso foram de $0,31 \pm 0,11 \%$ na TG e $2,57 \pm 0,74 \%$ na TS (Fig. 3 ) $(\mathrm{P} \leq 0,001)$. Este resultado demonstra que a TS produz neuroma mais organizado e com maior chance de proliferação de tecido nervo. Assim, o tecido cicatricial produzido pela TS favoreceria a regeneração nervosa.

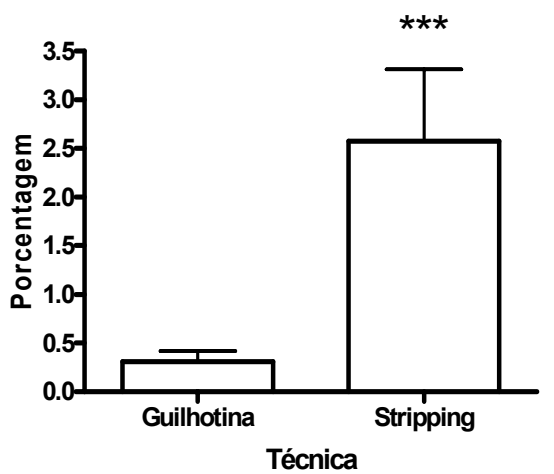

Figura 3. Porcentagem média ( \pm erro-padrão) de tecido nervoso no tecido cicatricial pós-cirúrgico de eqüinos submetidos a duas técnicas de neurectomia digital: guilhotina e stripping. $* * *$ Diferem entre si (teste $\mathrm{t}$, $\mathrm{P} \leq 0,001)$

Said et al. (1984) descreveram histologicamente a formação de neuromas em eqüinos dois a quatro meses após a realização das neurectomias. Nos casos considerados dolorosos, ocorreu maior proporção de tecido nervoso e, nos não dolorosos, maior porcentagem de tecido conjuntivo. Baseado nessas informações, poderse-ia inferir que a TS teria maior predisposição para a formação de neuromas dolorosos. Contudo, essa hipótese não se confirmou, pois, em um estudo clínico, Faleiros et al. (2008) verificaram apenas sensibilidade discreta na cicatriz proximal, quatro meses após a cirurgia, sendo sua incidência maior $(\mathrm{P}=0,003)$ nos nervos submetidos à TG $(56,6 \%)$ que nos submetidos à TS $(6,6 \%$,).

\section{CONCLUSÕES}

$\mathrm{Na}$ avaliação macroscópica, não se observou diferença no volume da cicatriz do coto proximal, entre as técnicas usadas, indicando que a agressão cirúrgica e as condições inflamatórias foram semelhantes, e nenhuma das técnicas foi capaz de prevenir a regeneração nervosa. O retorno da sensibilidade nervosa deve demorar mais a ocorrer após a TS, devido à maior distância entre cotos, contudo a maior proporção de tecido nervoso no tecido cicatricial sugere que o uso dessa técnica favorece a regeneração nervosa.

\section{AGRADECIMENTO}

Ao Departamento de Patologia Geral - ICBUFMG, por ceder os equipamentos para histomorfometria.

\section{REFERÊNCIAS BIBLIOGRÁFICAS}

BLACK, J.B. Palmar digital neurectomy: an alternative surgical approach. Proc. Am. Assoc. Equine Pract., v.38, p.429-432, 1992.

CUMMINGS, J.F.; FUBINI, S.L.; TODHUNTER, R.J. Attempts to prevent equine post neurectomy neuroma formation through retrograde transport of two neurotoxins, doxorubicin and ricin. Equine Vet. J., v.20, p.451-456, 1988.

DABAREINER, R.M.; NATHANIEL, A.W.; SULLINS, K.E. Comparison of current techniques for palmar digital neurectomy in horses. Soft-Tissue Surg., v.43, p.231-232, 1997.

DELISTOIANOV， N.; MACORIS， D.G.; GODOY, R.F. et al. Comparação entre duas técnicas de neurorrafia do digital palmar em eqüinos. Arq. Bras. Med. Vet. Zootec., v.58, p.44-51, 2006.

DUQUE, J.C.; VALADÃO, C.A.A.; FARIAS, A. et al. Pré-emptive epidural ketamine or $\mathrm{S}(+)-$ ketamine in post-incisional pain in dogs: a comparative study. Vet. Surg., v.33, p.361-367, 2004.

FALEIROS, R.R.; ALVES, G.E.S.; MARQUES JR., A.P. Dor aguda: vias anatômicas, bioquímicas e fisiopatologia. Cad. Tec. Esc. Vet. $U F M G$, n.21, p.5-14, 1997.

FALEIROS, R.R.; TINTO, J.J.R.; ESCOBAR, A. et al. Neurectomia digital em eqüinos: comparação das técnicas guilhotina e stripping. Arq. Bras. Med. Vet. Zootec., v.60, p.335-340, 2008 
GRECCO, M.A.S.; LEITE, V.M.; ALBERTONI, W.M. et al. Estudo da regeneração nervosa em nervos tibiais de ratos Wistar utilizando o Fluoro-Gold como marcador neuronal. Acta Ortop. Bras., v.11, p.225-229, 2003.

HAUGLAND, L.M.; COLLIER, M.A.; PANCIERA, R.J. et al. The effect of $\mathrm{CO}_{2}$ laser neurectomy on neuroma formation and axonal regeneration. Vet. Surg., v.21, p.351-354, 1992.

JACKMAN, B.R.; BAXTER, G.M.; DORAN, R.E. et al. Palmar digital neurectomy in horses. Vet. Surg., v.22, p.285-288, 1993.

LUNA, L.G. Manual of histologic staining methods of the Armed Forces Institute of Pathology. 3.ed. New York: Mc Graw Hill, 1968.
SAID, A.H.; KHAMIS, Y.; MAHFOUZ, M.F. et al. Clinicopathological studies on neurectomy in equids. Equine Vet. J., v.16, p.442-446, 1984.

SCHNEIDER, R.K.; MAYHEW, I.G.; CLARKE, G.L. Effects of cryotherapy on the palmar digital nerves in the horse. Am. J. Vet. Res., v.46, p.7-12, 1985.

STOPIGLIA, A.J.; LAINETTI, R.D.; PIRES, R.S. et al. Avaliação morfométrica de fibras nervosas do nervo ulnar após reparação cirúrgica com auto-enxerto e prótese tubular em cães. Braz. J. Vet. Res. Anim. Sci., v.35, p.80-83, 1998.

TURNER, A.S.; TROTTER, G.W.; POWERS B.E. Evaluation of tissue adhesive to contain axonal regeneration in horses. Vet. Surg., v.24, p.308-314, 1995. 